https://helda.helsinki.fi

\title{
Tacit knowledge in teacher education
}

\section{Toom, Auli}

Springer

2019-12-15

Toom , A 2019 , Tacit knowledge in teacher education . in M A Peters (ed.), Encyclopedia of Teacher Education . Springer , Singapore . https://doi.org/10.1007/978-981-13-1179-6_177-1

http://hdl.handle.net/10138/337567

https://doi.org/10.1007/978-981-13-1179-6_177-1

unspecified

acceptedVersion

Downloaded from Helda, University of Helsinki institutional repository.

This is an electronic reprint of the original article.

This reprint may differ from the original in pagination and typographic detail.

Please cite the original version. 


\title{
Tacit Knowledge in Teacher Education
}

\author{
Auli Toom, PhD, Professor of Higher Education \\ Centre for University Teaching and Learning \\ University of Helsinki, Helsinki, Finland \\ auli.toom@helsinki.fi
}

\section{Introduction}

This chapter considers teacher's tacit knowledge and knowing in the context of pre-service teacher education. It highlights the essential role of tacit knowledge and knowing in teacher's knowledge base and for skilful teaching, considers it in relation to teacher competence, and at the same time, reflects on the challenges related to it among early career teachers. The chapter emphasises the importance of preservice and early career teachers' awareness of tacit knowledge and knowing in teachers' work requiring both extensive educational vision and thinking as well as quick and reasoned decision-making in complex professional situations in classroom and in professional communities. The chapter discusses how tacit knowledge and knowing could be elaborated, reflected and cultivated in pre-service teacher education. It also presents a concrete pedagogical model with which the tacit knowing could be tackled in the practice of teaching and explicated thoroughly. The crucial role of pedagogical practices in teacher education is emphasised.

\section{Teacher's Tacit Knowledge and Knowing}

Teacher's professional practical knowledge has been investigated relatively extensively, and it is agreed that it consists of conceptions, principles and practices that are useful for everyday work at school. Teacher's tacit knowledge and knowing are aspects of teacher's practical knowledge covering competence to act professionally. Characteristic for teacher's tacit knowledge is that it is partly implicit and it covers teachers' beliefs, attitudes and values that are accumulated through their personal experiences, and rooted more broadly to professional tradition and community. Teacher's tacit knowing means especially capability to act skilfully and tactfully in quick classroom interaction or professional interaction situations that require immediate situational analysis, interpretation, understanding, decision-making and action in a student-oriented and sensitive way (cf. Polanyi, 1966). It is similar to teacher competence consisting of knowledge, skill and ability to act in professional situations as well as explicate the course of action and justify it. It allows the teacher to follow the planned course of action, and at the same time to take into account the situational cues and requirements as well as needs 
of students, colleagues and others involved in the situation. Teachers can explicate and justify their tacit knowing practically, which also allows to grasp it in research (Fenstermacher, 1994; Toom, 2012).

The quick "pedagogical moments" that teachers continuously face with students in classroom interaction can be complex and dilemmatic, or they can be empowering and they involve a variety of intertwined social, academic, pedagogical, and moral aspects in the situation. In these moments, teachers aim to make reasonable and sustainable decisions, fulfil students' needs and act according to their broader educational vision. Characteristic to these moments is that teachers utilise a variety of their professional resources - knowledge, skills, competence -for the best of students and in the professional teacher role as authentic persons (Lampert, 1998; Toom \& Husu, 2018).

Pedagogical moments requiring teachers' immediate decision-making and action - or non-action - are not easy to identify in the classroom interaction, and they are not easy to solve. The pedagogical moments emerge in the immediacy and hastiness of the lessons and they stem from the needs of the students in relation to the issues in which students are involved both socially and academically. They suppose teacher's tacit knowing - presence, authenticity and tactfulness - in relation to students and their needs, and especially capability to respond to the situation in a best suitable way. This capability is related to skilful teaching, teacher's experience, confidence and expertise as pedagogical professional. Thus, it is challenging to grasp as a personal experience in pre-service teacher education and due to its' characteristics, it is challenging to demonstrate or grasp for student teachers. Still, tacit knowing is a key component in skilful teaching and in solving dilemmatic pedagogical moments, so a variety of authentic descriptions, examples and real classroom cases and their analysis can be helpful in representing tacit knowing in practice.

\section{Understanding Crucial Role of Tacit Knowledge and Knowing in Teaching}

It is crucial that pre-service teachers learn the key capabilities for their work during teacher education. This covers knowledge and skills related to student learning, teaching, and education; well-being at school, school development and teacher's own learning and development as professionals. There are often negotiations and even challenges related to the pre-service teacher education curricula in deciding the core contents, and the tendency to emphasise theoretical and subject-specific knowledge related to teaching instead of thorough application of knowledge and learning from and through practice. Learning the skills and expertise in teaching requires time, and pre-service teachers often reach the level of managing the practice of teaching sufficiently. This tendency might make it challenging to demonstrate the importance of the teaching skills and especially the crucial role of tacit knowing intertwined in it. 
In line with this, pre-service teacher education curricula and courses tend to focus on enhancing basic knowledge and skills for teachers and teaching and often keeping in mind the basic education curricula and the regulations that the schools follow at the moment. These less often emphasise the importance of deep educational understanding, require expertise in teaching or highlight aspects of tacit knowing crucial for teaching although it is a crucial component in teacher's professionalism. This is partly because of prioritising some other issues related to teacher's work, and partly because of the challenges, time and practising required for learning of teaching expertise and professionalism. Tacit knowing is also such professional capability and intertwined on a variety of professional and interactive situations that it is challenging to grasp or tackle on it during some single courses. It is not possible to estimate the threshold level of teacher's tacit knowing for early career teachers and it either cannot be exposed to assessment in the same way as specific content knowledge or skills, so these aspects might also complicate its integration to pre-service teacher education. Currently, it is very much upon teacher educators' estimations how much and in which ways they integrate the perspectives of tacit knowing in their courses.

Emphasis on teacher's tacit knowing would require deep understanding of the phenomenon among the teacher educators and its crucial role in teacher's skilful action. It also requires constant intertwining the theoretical knowledge and practice of teaching in a variety of ways, and active role of student teachers in terms of their learning in teacher education. Extensive four- and five-year teacher education programmes - in principle - would allow cultivating tacit pedagogical knowing among student teachers because it requires time and constant practicing, analysis and reflection. If teaching methods are utilised in a reasonable way in pre-service teacher education, student teachers may build the capacity to make use of their tacit pedagogical knowing in pedagogical moments in interactive situations, monitor the course of the lesson and act sensitively in relation to students and their learning. The inability to utilise their tacit pedagogical knowing might lead student teachers to follow their prepared lesson plan in an unreflective way and lead to rigid practices in the interactive situations with students. This might even create unfavourable conditions for student learning in classroom situations.

\section{Uncovering Tacit Knowledge and Knowing in Teacher Education}

Uncovering tacit knowledge and knowing among pre-service teachers does not happen automatically, but rather it requires systematic and conscious pedagogical effort from teacher educators. It especially calls for pedagogies and practices that connect the practice of teaching, possibility to observe and reflect on the practice, consider the alternative ways of action and relate them with the research literature. Research on teacher education and pre-service teacher learning emphasises the importance of reflection for, in and on teaching, but focus on tacit knowledge and knowing is less emphasised. Still, the need to 
focus on tacit knowledge and knowing aspects in pre-service teacher education would be important due to their key role in teaching, interaction with students and in the practical work of teaching. Tacit pedagogical knowing is in many ways similar to tactfulness or competence in a sense that it covers knowledge, skills and ability to act in a sensible and sensitive ways in pedagogical moments. Tacit pedagogical knowing is not always easy to grasp because it is intertwined to practice of teaching and unique interactive situations. In pedagogical moments beyond the prepared lesson plan, teachers rely on their tacit pedagogical knowing when trying to navigate in the situation and find a reasonable and deliberate solution.

Tacit pedagogical knowing in integrated to the practice of teaching, and thus, in order to cultivate it effectively in pre-service teacher education the practice of teaching needs to be brought in one way or another in student teachers' learning situations. The practice of teaching can be elaborated through analysing authentic and complex classroom cases, critical incidents in teaching, visioning alternative interpretations and strategies for solving them and reflecting on the reasons behind the cases. The systematic and collaborative analysis of the cases would equip student teachers with a variety of reasoned schemes and strategies. The tacit pedagogical knowing can also be extracted from the practice of teaching though the procedure of guided reflection (Husu, Toom \& Patrikainen, 2008; ACTTEA 2012-15 http://acttea.ut.ee) that combines video recorded authentic classroom situations "pedagogical moments" and their systematic reflection with the help of the video (see Figure 1). Video allows observing the authentic classroom situation several times, perceiving the situational cues, thinking about a variety of interpretations as well as explicating and accumulating tacit pedagogical knowing. It also allows observing other student teachers' videoed "pedagogical moments", listening their and the more experienced teacher educators' and supervisors' reflections, and learning about them. Authentic classroom cases or videorecorded pedagogical moments trigger student teachers' tacit pedagogical knowing even if the cases and videos are not from their own experiences or teaching. 


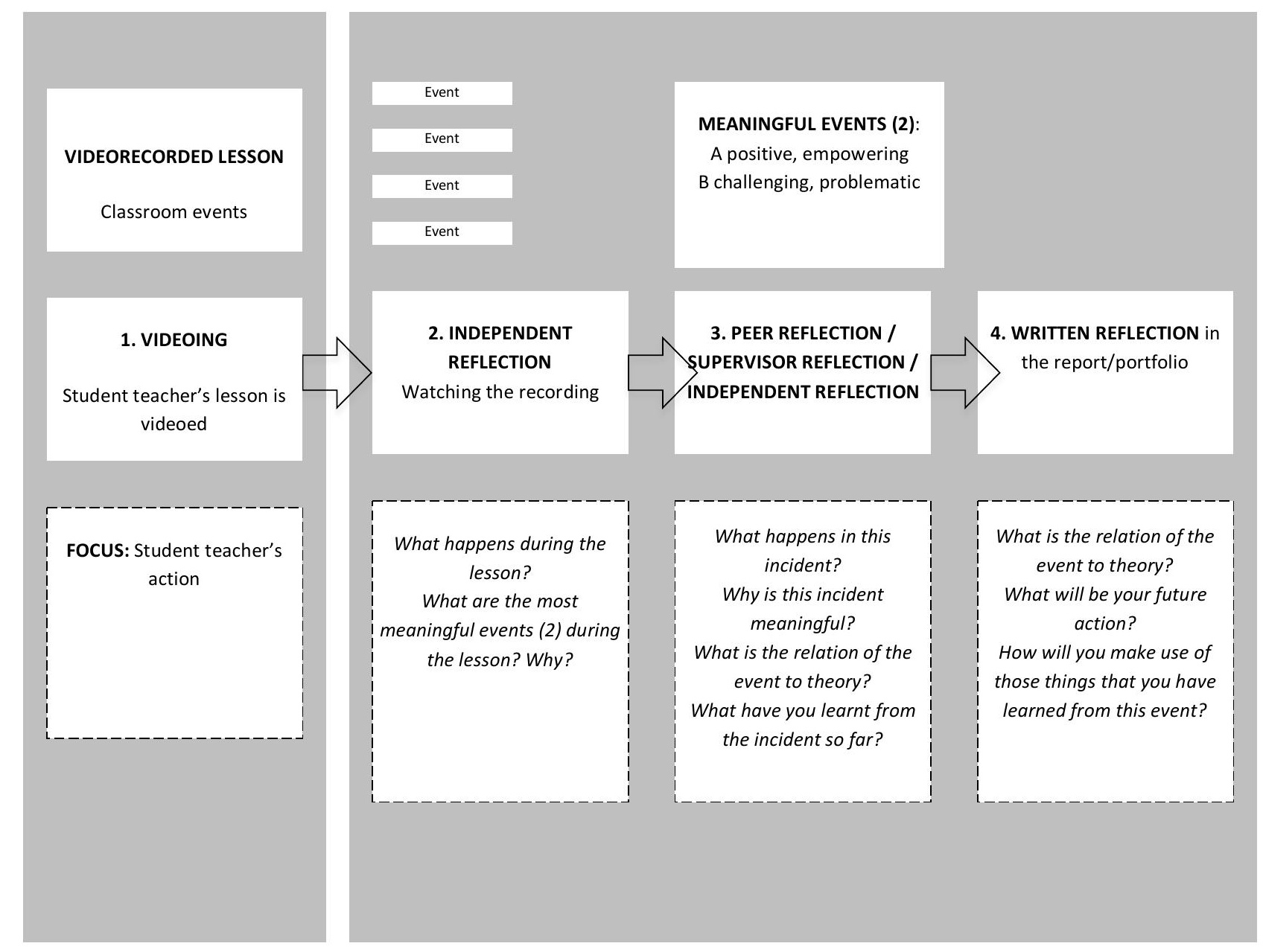

Figure 1. The procedure of guided reflection to extract tacit knowing (cf. Husu et al., 2008; Toom et al., 2015; ACTTEA 2012-2015).

The key to cultivate student teachers' tacit pedagogical knowing as a key component of skilful teaching in pre-service teacher education, is to support its learning throughout the programme in a variety of ways both in small details of classroom interaction as well as in broad educators' role. When choosing this kind of emphasis to pre-service teacher education, it would guide and foster teacher educators to integrate this aspect to their courses, teaching and supervision as well. Cultivating tacit pedagogical knowing in a variety of ways could ideally lead to extensive discussions on tactfulness in pedagogical situations from different perspectives and guide student teachers' learning to become thoughtful and considerate teachers. Tacit pedagogical knowing can be practiced in multiple different ways, and there are no right or easy answers to the pedagogical moments in classroom interaction. Longer perspective and different possibilities for observing and practicing tacit pedagogical knowing may support student teachers' meaningful growth as professional teachers. 
In pre-service teacher education, experienced teachers could also be utilised as resources for enhancing student teachers' tacit pedagogical knowing. Discussions with experienced teachers, observation of their classroom teaching, co-teaching together with them, modelling their professional practices and involving them to reflect on their professional work would allow the early career teachers to realise the spectrum of tacit pedagogical knowing and expertise capture to it. Also providing mentoring for early career teachers during the first years in the profession has been suggested as a key element in enhancing tacit pedagogical knowing. The early years can be burdening due to different reasons, and especially the gap between theoretically focused teacher education studies and often messy and hasty practice of teaching might be confusing. In this phase, the mentoring and support from an experienced teacher might help in relying on one's own tacit pedagogical knowing, learning from the practice of teaching and constructing one's own way for doing teacher's work. Teacher education institutes could even build in-service teacher education programmes for experienced teachers where they could explicate and cultivate their tacit pedagogical knowing and make use of their capability with other experienced teachers. This might be supportive for them in raising their awareness of tacit pedagogical knowing as a resource related to and stemming from the practice of teaching.

\section{Conclusion}

In order to do teacher's work professionally and skilfully and fulfilling the needs of students and school community, teachers need to be capable of utilising their tacit knowledge and knowing capacities in interactive situations requiring quick and considered decision-making in professional contexts. Tacit knowledge and knowing accumulate in the professional practice of teaching in interaction with students and colleagues, through reflection and throughout the professional career. The emphasis on tacit aspects of teaching and tacit pedagogical knowing might help student teachers in their transition from preservice teacher education to the real teacher's work. When student teachers are faced with the hastiness and intensity of teacher's work, intellectual and practical capacities the work requires, and both long term vision and immediate decision-making already during teacher education, the transition may be smoother for them. They are prepared in utilising their tacit pedagogical knowing capacity in the interaction with students, relying on it in a reasoned way and enhancing it systematically during their career. They are prepared to learn and develop as professionals and make deliberate decisions in the pedagogical moments for the best of student learning.

\section{References}

Fenstermacher, G.D. (1994). The knower and the known: The nature of knowledge in research on teaching. In L. Darling-Hammond (Ed.), Review of Research in Education, 20 (pp. 3-56). Washington: American Educational Research Association.

Husu, J., Toom, A. \& Patrikainen, S. (2008). Guided reflection as a means to demonstrate and develop student teachers' reflective competencies. Reflective Practice, 9(1), 37-51. 
Lampert, M. (1998). Studying teaching as a thinking practice. In J. Greeno \& S. G. Goldman (Eds.), Thinking practices (pp. 53-78). Hillsdale, NJ: Lawrence Erlbaum.

Polanyi, M. (1966/1983). The tacit dimension. Gloucester, MA: Peter Smith/Doubleday \& Company, Inc.

Toom, A. (2012). Considering the artistry and epistemology of tacit knowledge and knowing. Educational Theory, 62(06), 621-640.

Toom, A. \& Husu, J. (2018). Teacher's work in changing educational contexts: Balancing the role and the person. In H. Niemi, A. Toom, A. Kallioniemi \& J. Lavonen (Eds.), The teacher's role in the changing globalizing world (pp. 1-9). Leiden: Brill. 